\title{
Necrotizing Fasciitis of the Extremity Caused by Haemophilus influenzae Serotype b in a Healthy Adult
}

\author{
Ellen Y. Lee MD, Wing Yuk Ip MD, FRCS (Ed), FHKAM (Ortho)
}

Received: 23 April 2009/Accepted: 23 September 2009/Published online: 17 October 2009

(C) The Association of Bone and Joint Surgeons \& 2009

\begin{abstract}
Haemophilus influenzae is a rare cause of necrotizing fasciitis with only a few previously reported cases. We describe the case of a 44-year-old man who had necrotizing fasciitis of the right lower extremity develop after intramuscular injections of paracetamol on his right buttock. The causative organism isolated was Haemophilus influenzae serotype $b$. This unusual infection was treated with repeated débridement and cultureguided antibiotics. There was no recurrence of infection at last followup 1 year after the initial surgery. Wound coverage was achieved with the use of a full-thickness skin graft after application of platelet-rich plasma and a dermal regeneration template. This resulted in a cosmetically acceptable appearance of the involved extremity for our patient.
\end{abstract}

Each author certifies that she has no commercial associations (eg, consultancies, stock ownership, equity interest, patent/licensing arrangements, etc) that might pose a conflict of interest in connection with the submitted article.

Each author certifies that her institution approved the reporting of this case report, that all investigations were conducted in conformity with ethical principles of research, and that informed consent for participation in the study was obtained.

\section{E. Y. Lee $(\bowtie)$}

Department of Orthopaedics, Section of Hand and Microsurgery, University of the Philippines, Philippine General Hospital, Taft Avenue, Ermita, Manila 1000, Philippines

e-mail: dr_ellen_lee@yahoo.com

W. Y. Ip

Division of Hand and Foot Surgery, Department of Orthopaedics and Traumatology, University of Hong Kong, Queen Mary

Hospital, 102 Pokfulam Road, Hong Kong, China

\section{Introduction}

Necrotizing fasciitis is a life-threatening, rapidly progressive infection. A review of the literature showed only two reported cases of lower limb infection caused by Haemophilus influenzae serotype $b$, one in an infant and one in an elderly patient with diabetes $[3,11]$. We report the case of a healthy 44-year-old man who had $\mathrm{H}$ influenzae serotype $b$ necrotizing fasciitis develop after intramuscular paracetamol injections.

\section{Case Report}

A 44-year-old man with good past health was given serial intramuscular injections of paracetamol in his right buttock for fever, cough, and cold in a community clinic. After three injections, the patient was still febrile and felt severe pain over his right buttock and lateral thigh. The right gluteal region became dusky with an erythematous margin. Emergency radical débridement was performed in a private hospital with the patient under general anesthesia. The findings of necrotic dermis, grayish fascia not adherent to underlying muscle, and foul-smelling "dishwater" pus prompted the operative diagnosis of necrotizing fasciitis. Intraoperative specimens sent for culture grew $\mathrm{H}$. influenzae serotype b. The histology report showed acute necrotizing suppurative inflammation. The débridement resulted in a skin defect over the right gluteal region that was left open with dressings. The patient was empirically started on intravenous ceftazidime and ciprofloxacin and oral clarithromycin for broad-spectrum coverage. Susceptibility of the organism to these three antibiotics eventually was confirmed by culture sensitivity results. Two days after the initial surgery, the patient was still febrile and had 


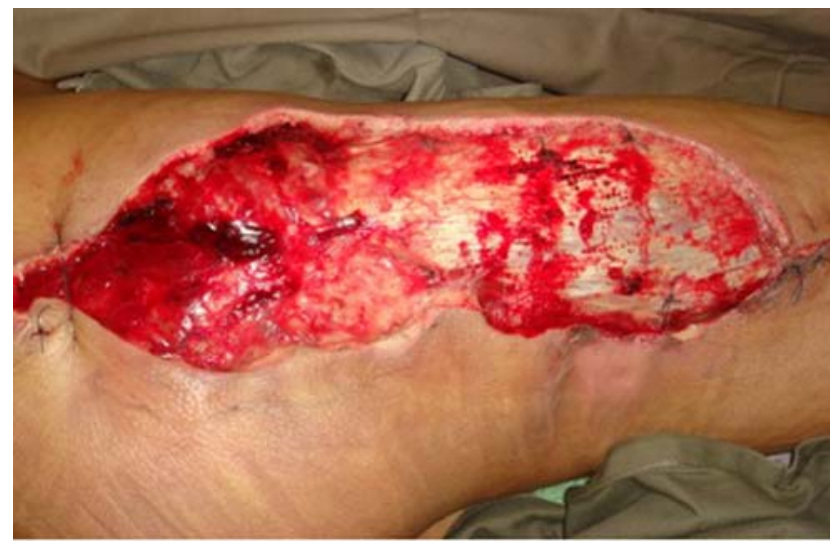

Fig. 1 A photograph shows the skin defect $(23.5 \mathrm{~cm}$ long $\times 7 \mathrm{~cm}$ wide) after repeated débridements.

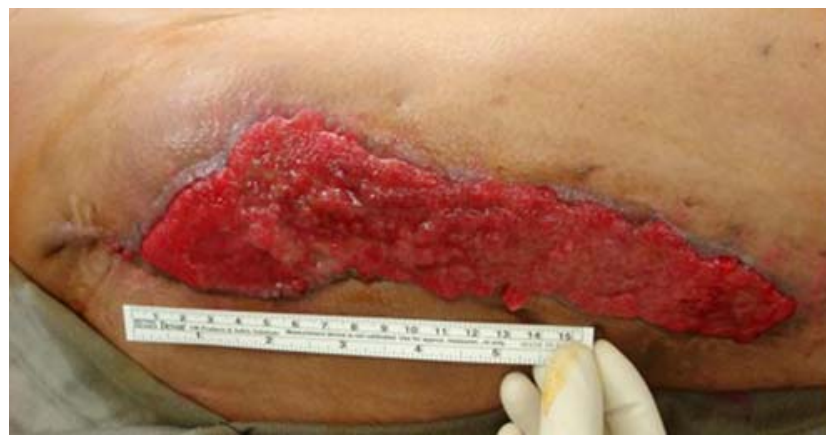

Fig. 2 The final defect after application of APG with PRP is shown.

severe pain, erythema, and fluctuance over his right flank. The patient was returned to the operating room and examination of the area of necrosis showed it had progressed to the patient's right flank, entire buttock, and lateral thigh. Radical débridement was repeated.

Progression of the necrosis and the patient's persistently febrile state after undergoing two radical débridements and receiving intravenous antibiotics prompted transfer to our institution after the second débridement. He was still febrile with leukocyte counts as high as $24.1 \times 10^{9} / \mathrm{L}$. Our infectious disease consultant shifted the patient's medication to intravenous ceftriaxone and stopped all other antibiotics. The infection eventually was controlled with a third radical débridement followed by a fourth 48 hours later, but the patient was left with a $23.5-\mathrm{cm}-$ long by $7-\mathrm{cm}-$ wide full-thickness skin defect over his right lateral hip and thigh (Fig. 1). This was treated by applying platelet rich plasma (PRP) in the form of autologous platelet gel (APG) after local débridement during the fifth surgery five days after the fourth surgery. Six days later the patient had application of an Integra ${ }^{\mathbb{R}}$ dermal regeneration template (Integra LifeSciences Corp, Plainsboro, NJ). The coverage of the final 21-cm $\times 6.5-\mathrm{cm}$ defect (Fig. 2) was achieved with a meshed $10-\mathrm{cm} \times 5-\mathrm{cm}$ full-thickness skin graft

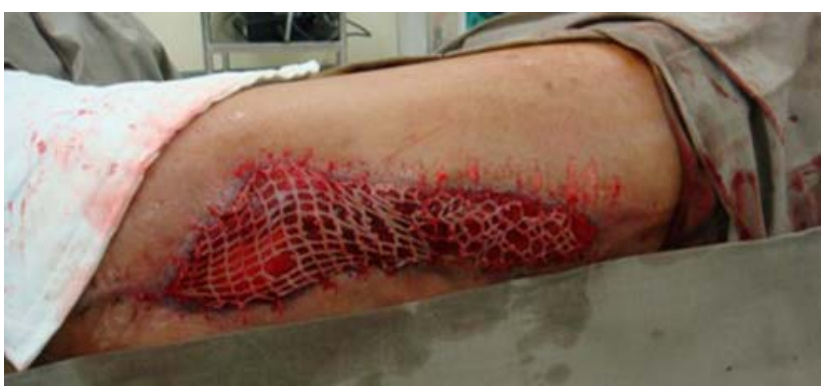

Fig. 3 A photograph shows the application of a meshed 10-cm $\times 5$ $\mathrm{cm}$ full-thickness skin graft.

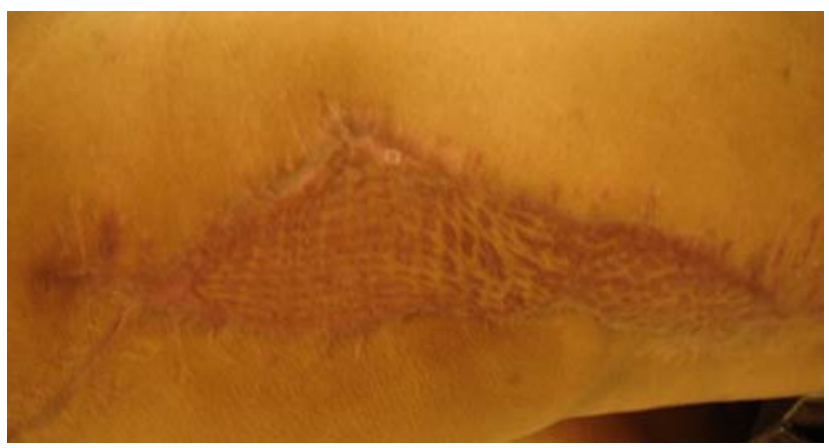

Fig. 4 A photograph taken 8 months after the full-thickness skin graft shows the healed defect.

harvested from the groin on the seventh and final surgery one month later (Fig. 3). The donor site was closed primarily. Donor and recipient sites healed uneventfully in 2 weeks. Eight months after the last surgery, the skingrafted area had further decreased in size (Fig. 4). There was no recurrence of infection one year after surgery. The patient was satisfied with the final appearance of his right groin and thigh.

\section{Discussion}

$\mathrm{H}$ influenzae serotype $\mathrm{b}$ was a well-known cause of invasive disease, such as meningitis and pneumonia with bacteremia in children younger than 2 years during the pre$\mathrm{H}$ influenzae serotype $\mathrm{b}$ vaccination era [7]. A review of the current literature showed only four reported cases of necrotizing fasciitis of the extremity caused by $\mathrm{H}$ influenzae $[3,7,11,13]$. Two were caused by $\mathrm{H}$ influenzae serotype $b[3,11]$. The first case was that of a lower limb necrotizing fasciitis in a 13-month-old infant [3]. The second reported the case of an elderly patient with diabetes presenting with spontaneous painful swelling of the left leg [11]. There was also one published case of cellulitis and thigh abscess in a 41-year-old man with high alcohol consumption and chronic pansinusitis caused by $\mathrm{H}$ influenzae serotype b [4]. Our Medline search showed no 
reports of $\mathrm{H}$ influenzae serotype $\mathrm{b}$ necrotizing fasciitis in a healthy adult.

Reviews of necrotizing fasciitis reported Streptococcal, Staphylococcal species, Enterococci, and Enterobacteriaceae as the more common organisms isolated [6, 9, 14]. $\mathrm{H}$ influenzae was not isolated in any of the reported cases [6, $9,14]$. Mortality rates ranged from $9.3 \%$ to $34 \%$. Amputation was necessary for infection control in $6 \%$ to $22.5 \%$ of patients [6, 9, 14]. These reviews emphasized the need for early diagnosis and prompt débridement with necrotizing fasciitis.

Our patient underwent five débridements and two additional coverage procedures for disease resolution without amputation. Radical débridement was performed every 48 hours initially to afford a viable full-thickness skin edge with healthy fascia and muscle bed. Persistent infection prompted referral and transfer of the patient from a private hospital to a tertiary university hospital. Intensive medical support sustained him through his septic state and multiple surgeries. Antibiotic treatment was susceptibility guided and tailored by the infectious disease expert.

Our patient was not immunocompromised and showed no signs of Varicella infection. Necrotizing fasciitis developed at the patient's intramuscular paracetamol injection site. Several reports link intramuscular injections of NSAIDs to the development of necrotizing fasciitis [2, $4,12,15]$. In a recent case-control study, NSAIDs and paracetamol were associated with necrotizing fasciitis on univariate analysis but only NSAIDs were an independent risk factor after multivariate analysis [12]. Potential mechanisms peculiar to NSAID injections include NSAIDinduced necrosis of injection sites and secondary colonization, NSAID inhibition of inflammatory reaction and antibacterial defense, or delay in treatment attributable to masking of symptoms by NSAIDs [2, 12]. The case of $\mathrm{H}$ influenzae thigh abscess also developed over an intramuscular phenylbutazone injection site [4]. We postulate the patient's cough and cold may have been the focus of $\mathrm{H}$ influenzae and the intramuscular injection site either was infected by contaminated fluid or secondarily colonized.

Infection control was achieved in our patient with susceptibility-guided antibiotics and prompt aggressive débridements. The patient's concern for cosmesis and donor site morbidity prompted the use of APG containing PRP and a dermal regeneration template (Integra ${ }^{\circledR}$ ). Autologous platelet concentrates contain multiple growth factors that potentially can accelerate tissue repair mechanisms [5, 8, 10]. APG-treated full-thickness punch biopsy wounds in healthy volunteers had increased wound closure rates compared with control wounds treated with antibiotic ointment during a 42-day period when evaluated by visual clinical inspection of digital photographs, and by digital planimetry photographic measurement [5]. APG was used in our patient as an adjunct in preparing a viable graft bed. Additional comparative studies are needed to determine whether it had any significant contribution in decreasing wound size.

Integra ${ }^{\circledR}$ is an artificial dermal substitute developed in the late 1970s to achieve early wound coverage after excision of extensive burn injuries [1]. Integra ${ }^{\circledR}$ does not have any antimicrobial activity, thus was susceptible to rapid degeneration if applied on nonviable tissue that was prone to infection [1]. The use of Integra ${ }^{\circledR} \operatorname{did}$ not result in additional infection for our patient. However, its importance in facilitating wound coverage is unclear. The use of a full-thickness skin defect allowed primary closure of the donor site from the groin area and satisfied our patient's concerns about having another visible scar.

Aggressive surgical débridement was crucial in our management of this rare case of $H$ influenzae serotype $b$ necrotizing fasciitis of the lower extremity. There was no recurrence of infection 1 year after the initial surgery.

Acknowledgments We thank Dr. Evelyn Kuong for help in documenting this case.

\section{References}

1. Akhtar S, Hasham S, Abela C, Phipps AR. The use of Integra ${ }^{\mathrm{TM}}$ in necrotizing fasciitis. Burns. 2006;32:251-254.

2. Aronoff DM, Bloch KC. Assessing the relationship between the use of nonsteroidal antiinflammatory drugs and necrotizing fasciitis caused by group A streptococcus. Medicine (Baltimore). 2003;82:225-235.

3. Collette CJ, Southerland D, Corrall CJ. Necrotizing fasciitis associated with Haemophilus influenzae type b. Am J Dis Child. 1987;141:1146-1148.

4. Hartmann D, Grehn M, Vontobel H, Gurtner B. Haemophilus influenzae type b septicaemia associated with myonecrosis and thigh abscess. Eur J Clin Microbiol Infect Dis. 1988;7:176-178.

5. Hom DB, Linzie BM, Huang TC. The healing effects of autologous platelet gel on acute human skin wounds. Arch Facial Plast Surg. 2007;9:174-183.

6. Liu YM, Chi CY, Ho MW, Chen CM, Liao WC, Ho CM, Lin PC, Wang JH. Microbiology and factors affecting mortality in necrotizing fasciitis. J Microbiol Immunol Infect. 2005;38:430-435.

7. McLellan E, Suvarna K, Townsend R. Fatal necrotizing fasciitis caused by Haemophilus influenzae serotype f. J Med Microbiol. 2008;57:249-251.

8. Obremskey WT, Marotta JS, Yaszemski MJ, Churchill LR, Boden SD, Dirschl DR. Symposium. The introduction of biologics in orthopaedics: issues of cost, commercialism, and ethics. J Bone Joint Surg Am. 2007;89:1641-1649.

9. Ogilvie CM, Miclau T. Necrotizing soft tissue infections of the extremities and back. Clin Orthop Relat Res. 2006;447:179-186.

10. Rozman P, Bolta Z. Use of platelet growth factors in treating wounds and soft-tissue injuries. Acta Dermatovenerol Alp Panonica Adriat. 2007;16:156-165.

11. Saito T, Matsunaga H, Matsumura Y, Segawa H, Takakura S, Nagao M, Iinuma Y, Miyachi Y, Ichiyama S. Necrotizing fasciitis caused by Haemophilus influenzae type $\mathrm{b}$ in an elderly patient. J Clin Microbiol. 2009;47:852-854. 
12. Souyri C, Olivier P, Grolleau S, Lapeyre-Mestre M; French Network of Pharmacovigilance Centres. Severe necrotizing softtissue infections and nonsteroidal anti-inflammatory drugs. Clin Exp Dermatol. 2008;33:249-255.

13. Stumvoll M, Fritsche A. Necrotizing fasciitis caused by unencapsulated Haemophilus influenzae. Clin Infect Dis. 1997;25:327.
14. Wong CH, Chang HC, Pasupathy S, Khin LW, Tan JL, Low CO. Necrotizing fasciitis: clinical presentation, microbiology and determinants of mortality. J Bone Joint Surg Am. 2003;85:1454-1460.

15. Verfaillie G, Knape S, Corne L. A case of fatal necrotizing fasciitis after intramuscular administration of diclofenac. Eur $J$ Emerg Med. 2002;9:270-273. 